Retraction

\title{
Retraction: Calvo-Guirado, J.L., et al. The Use of Tooth Particles as a Biomaterial in Post-Extraction Sockets. Experimental Study in Dogs. Dent. J. $2018,6,12$
}

\author{
Dentistry Journal Editorial Office
}

MDPI, St. Alban-Anlage 66, 4052 Basel, Switzerland; dentistry@mdpi.com

Received: 7 August 2020; Accepted: 10 August 2020; Published: 16 August 2020

We have been made aware that Figure 7d of paper [1] is similar to Figure 11a of a paper published in Applied Sciences [2]. Both figures show histological images from dogs for experiments carried out in different research projects. The authors were unable to provide an adequate explanation for the similarity. The Editor-in-Chief and the Editorial Office have therefore taken the decision to retract the paper [1].

The Dentistry Journal Editorial Office apologize to the readers of the Dentistry Journal for any inconvenience caused. To ensure the addition of only high-quality scientific works to the field of scholarly communication, this paper [1] is retracted and shall be marked accordingly. MDPI is a member of the Committee on Publication Ethics (COPE) and takes very seriously the responsibility to enforce strict ethical policies and standards.

\section{References}

1. Calvo-Guirado, J.L.; Maté-Sánchez de Val, J.E.; Ramos-Oltra, M.L.; Pérez-Albacete Martínez, C.; Ramírez-Fernández, M.P.; Maiquez-Gosálvez, M.; Gehrke, S.A.; Fernández-Domínguez, M.; Romanos, G.E.; Delgado-Ruiz, R.A. The Use of Tooth Particles as a Biomaterial in Post-Extraction Sockets. Experimental Study in Dogs. Dent. J. 2018, 6, 12. [CrossRef] [PubMed]

2. Calvo-Guirado, J.L.; Fernández-Domínguez, M.; Aragoneses, J.M.; Fernández-Bodereau, E.; Garcés-Villalá, M.A.; De Carlos-Villafranca, F;; Cabello-Colás, M.; Jiménez-López, R.; Pérez Albacete-Martínez, C.; Delgado-Ruiz, R.A. Experimental Study on the Influence of Apigenin $\mathrm{K}$ and Melatonin in Socket Preservation as Bone Stimulators: An Experimental Study in Beagle Dogs. Appl. Sci. 2020, 10, 3006. [CrossRef]

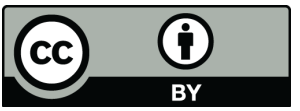

(C) 2020 by the author. Licensee MDPI, Basel, Switzerland. This article is an open access article distributed under the terms and conditions of the Creative Commons Attribution (CC BY) license (http://creativecommons.org/licenses/by/4.0/). 